\title{
Absence of effects of prolonged simvastatin therapy on nocturnal sleep in a large randomized placebo-controlled study
}

\begin{abstract}
A. C. $\mathrm{KEECH}^{1,2,3}$ J. M. ARMITAGE ${ }^{1,2}$, K. R. WALLENDSZUS ${ }^{1}$, A. LAWSON ${ }^{1}$, A. J. HAUER ${ }^{1}$, S. E. PARISH ${ }^{1} \&$ R. COLLINS ${ }^{1,2}$ for the Oxford Cholesterol Study Group

${ }^{1}$ MRC/ICRF Clinical Trial Service Unit \& Epidemiological Studies Unit, Nuffield Department of Clinical Medicine, University of Oxford, Radcliffe Infirmary, Oxford, ${ }^{2}$ Department of Cardiology, John Radcliffe Hospital, Oxford, UK and ${ }^{3}$ NHMRC Clinical Trials Centre, Public Health Building, University of Sydney, Sydney, NSW, Australia
\end{abstract}

1 It has been suggested that lipophilic HMG CoA reductase inhibitors, like lovastatin and simvastatin, may cause sleep disturbance.

2 Six hundred and twenty-one patients at increased risk of coronary heart disease were randomized in a single centre to receive $40 \mathrm{mg}$ daily simvastatin, $20 \mathrm{mg}$ daily simvastatin or matching placebo. To assess the effects of prolonged use of simvastatin on nocturnal sleep quality and duration, a sleep questionnaire was administered to 567 patients ( $95 \%$ of 595 survivors) at an average of 88 weeks (range: 44-129 weeks) after randomization.

3 The main outcome measures were sleep-related problems and use of sleepenhancing medications reported during routine study follow-up visits, and responses to the sleep questionnaire about changes in sleep duration and about various sleep events during the preceding month.

4 No differences were observed between the treatment groups in the frequency of sleep-related problems reported, in the proportion of follow-up visits at which such problems were reported, or in the use of sleep-enhancing medications. The numbers who stopped study treatment were similar in the different treatment groups, and no patient stopped principally because of insomnia. In response to the sleep questionnaire, there were no significant differences between the treatment groups in reports of various sleep events during the preceding month, except that slightly fewer patients allocated simvastatin reported waking often. No differences in sleep duration were observed.

5 This placebo-controlled trial does not indicate any adverse effects of prolonged treatment with simvastatin on systematically sought measures of sleep disturbance.

Keywords simvastatin sleep assessment randomized trial

\section{Introduction}

Inhibitors of 3-hydroxy-3-methylglutaryl-coenzyme A (HMG-CoA) reductase, a rate-limiting enzyme in hepatic cholesterol synthesis, are now widely used to lower elevated cholesterol. Drugs in this class are generally well tolerated [1], but it has been suggested that two of the HMG-CoA reductase inhibitors, lovastatin and simvastatin, may cause sleep disturbance. This has been attributed to the relative lipophilic nature of lovastatin and simvastatin (compared with pravastatin) allowing them to cross the blood-brain barrier [2]. The first reports of the effects of HMG-CoA reductase inhibitors on sleep were from small non-blind uncontrolled studies with conflicting results [3-6]. As disorders of sleep are associated with many factors (e.g. age, gender, socio- 
economic class, mental and physical health, drug therapy [7]), such uncontrolled and non-randomized studieswhich cannot take account of differences in these factors between those who receive the treatment of interest and those who do not-may be biased and, consequently, seriously misleading.

More recently, this issue has been addressed by randomized double-blind trials [8-15], but there are some difficulties in the interpretation of their results due to the relatively small numbers of patients studied [8-12], the very short duration of treatment [8-10, $12-14]$ or the absence of an untreated control group or period $[11,12,14,15]$. The present report is of a randomized placebo-controlled trial (Oxford Cholesterol Study) among 621 patients which was designed primarily to assess the prolonged effects of simvastatin on blood biochemistry and other measures of safety and tolerability [16]. As patients had already been in the study for several years, it provided an opportunity to assess in an unbiased manner the effects of long-term use of simvastatin on various measures of nocturnal sleep quality and duration.

\section{Methods \\ Eligibility and randomized treatment comparisons}

A detailed description of the design and 3-year followup results of the Oxford Cholesterol Study is reported elsewhere [16]. Men and women aged between 40 and 75 years with total blood cholesterol of $3.5 \mathrm{mmol}^{-1}$ or greater were eligible if their past medical history indicated that they were at higher than average risk of coronary heart disease and there was no particular reason for exclusion. Following an initial screening clinic visit and an 8-week single-blind placebo run-in period, eligible and compliant patients who agreed to participate were evenly randomized to take $40 \mathrm{mg}$ simvastatin, $20 \mathrm{mg}$ simvastatin or matching placebo each evening. After this randomization visit (at week zero), all patients were to be seen at 8 weeks, then at 12 weekly intervals for about 1 year, and then at 24 weekly intervals.

\section{Routine data collection}

At the initial screening visit, patients completed a detailed questionnaire about past medical and treatment history and about certain aspects of lifestyle (including coffee and alcohol intake), and were asked how long (to the nearest hour) they usually slept at night. Seated blood pressure was recorded and a nonfasting blood sample was taken for laboratory analysis. At each follow-up visit, patients were directly asked whether any one of a pre-specified list of 20 particular symptoms (including insomnia and fatigue) had occurred since the previous visit, and any other symptoms volunteered (e.g. difficulty getting to sleep) were also to be recorded. All hospital admissions, possible adverse drug reactions, compliance with study treatment and reasons for stopping study treatment were recorded. Additionally, at annual visits, details of concurrent medication (including prescription sleeping tablets) were recorded. Non-fasting blood samples were taken for laboratory analysis from all patients attending each follow-up visit.

\section{Sleep questionnaire}

During the first 6 months of 1991, all patients attending their routine follow-up clinic visit (irrespective of whether or not they continued to take study treatment) were asked to complete a self-administered questionnaire about their sleep patterns during the previous month. Clinic staff provided clarification and assistance to those patients who had difficulty in answering any of the questions. Patients who were no longer attending the clinic, none of whom was taking study medication, were not approached to complete the sleep questionnaire.

Questions 1 to 4 in the sleep questionnaire used were those devised by Jenkins and colleagues [17]. These asked how many nights during the last month the patient had experienced: (1) 'Trouble falling asleep'; (2) 'Waking several times per night'; (3) 'Trouble staying asleep (including waking far too early)'; and (4) 'Waking up after usual amount of sleep feeling tired and worn out'. A score of 0 indicated not at all, $1=1-3$ nights, $2=4-7$ nights, $3=8-14$ nights, $4=15-21$ nights, and $5=22-31$ nights (i.e. higher scores indicate more sleep disturbance). The Jenkins Total Sleep score, based on the sum of the responses to questions 1 to 4 (which ranges from 0 to 20), has been validated previously [17]. A further four questions (Questions 5 to 8 ) were asked to obtain further information about sleep patterns. Question 5, which asked about the number of nights with vivid dreams or nightmares during the last month, was included because such symptoms had been reported by two study patients during routine follow-up. Question 6 asked about the use of prescription sleeping tablets during the last month to help avoid any real effect on sleep patterns being obscured by differences in the use of sleep-enhancing medication between the treatment groups. Question 7 asked, for the previous night, the time of going to sleep and the time of waking so that sleep duration in minutes could be estimated. Question 8 asked whether the patient felt their average sleep duration was longer, shorter, or about the same as when they started the study. The internal validity of these additional questions (5-8) and the consistency of their responses with each other were examined within the study. Six months after first completing the sleep questionnaire, 354 patients completed it a second time so that the reproducibility of responses could also be assessed.

\section{Statistical analysis}

Assessment of the effects of treatment was to be based on (i) all routinely sought and volunteered symptoms reported; and (ii) the first sleep questionnaire completed 
by each patient. The principal comparisons were of patients allocated either simvastatin dose (which both produced very similar reductions in cholesterol [16]) vs patients allocated placebo, with subsidiary comparisons of $40 \mathrm{mg}$ daily simvastatin vs $20 \mathrm{mg}$ daily simvastatin. All comparisons were made by allocated treatment group among all patients completing a sleep questionnaire irrespective of compliance (i.e. 'intention-to-treat' analyses: except that those patients no longer attending followup clinics, none of whom was taking study medication, did not complete questionnaires). Proportions of patients with different event scores in the different treatment groups were compared using chi-squared tests for heterogeneity and trend. Sleep duration was expressed as mean and s.d.. The Jenkins Total Sleep Problem score was calculated by summing the scores for questions 1 to 4 and expressed as the geometric mean and s.d.. The validity of questions 5 to 8 was explored by considering the correlation coefficients with the Total Sleep Problem score. Reproducibility between the first and second questionnaire response was evaluated using test-retest correlation coefficients and weighted kappa statistics for ordinal scale data [18]. Two-sided $P$-values $(2 P)$ are used throughout, and differences are described as nonsignificant (NS) if $2 P>0.05$.

\section{Results}

Patient characteristics ( Table 1)

Six hundred and twenty-one patients were randomized into the study between January 1989 and May 1990.

The sleep questionnaire was administered at an average of 88 weeks (range: 44-129 weeks) after randomisation to patients attending clinic follow-up. At this time, there were 595 survivors and completed questionnaires were obtained from $567(95 \%)$. Baseline characteristics of these patients (Table 1) were very similar to those of the Six hundred and twenty-one originally randomised [16], and were well balanced between the treatment groups. Average sleep duration, coffee and alcohol intake, and usage of medications known to affect sleep patterns were similar at baseline in the different groups.

Compliance with the allocated study treatment was similar in the different treatment groups, with $>90 \%$ of scheduled treatment being taken (or death) by $85 \%$ of all randomised patients, and by $88 \%$ of those who completed questionnaires. The numbers of patients who had stopped study treatment for any reason other than death were also similar in the treatment groups (32 in $40 \mathrm{mg}$ daily simvastatin group vs 24 in $20 \mathrm{mg}$

Table 1 Patient characteristics at baseline by allocated treatment

\begin{tabular}{|c|c|c|c|}
\hline & $\begin{array}{l}\text { Simvastatin } \\
40 \text { mg daily }\end{array}$ & $\begin{array}{l}\text { Simvastatin } \\
20 \mathrm{mg} \text { daily }\end{array}$ & $\begin{array}{l}\text { Placebo } \\
\text { control }\end{array}$ \\
\hline \multicolumn{4}{|l|}{ Numbers of patients } \\
\hline Randomized & 206 & 208 & 207 \\
\hline Completing questionnaire & 191 & 189 & 187 \\
\hline \multicolumn{4}{|c|}{ Baseline characteristics of patients completing questionnaire } \\
\hline Age (years) & $63.2 \pm 7.6$ & $63.4 \pm 7.4$ & $63.5 \pm 7.4$ \\
\hline Weight $(\mathrm{kg})$ & $77.7 \pm 12.3$ & $78.4 \pm 11.7$ & $77.8 \pm 12.5$ \\
\hline Average sleep duration $(\mathrm{h})$ & $7.0 \pm 1.3$ & $7.0 \pm 1.3$ & $6.8 \pm 1.2$ \\
\hline Cups of coffee consumed per week & $17.2 \pm 18.4$ & $15.2 \pm 16.3$ & $16.0 \pm 17.1$ \\
\hline Average alcohol intake (units/month) & $36.1 \pm 51.7$ & $34.8 \pm 43.4$ & $37.5 \pm 60.7$ \\
\hline Male & $85 \%$ & $87 \%$ & $84 \%$ \\
\hline Current smokers & $15 \%$ & $12 \%$ & $13 \%$ \\
\hline Prior MI & $60 \%$ & $61 \%$ & $61 \%$ \\
\hline Other CHD & $65 \%$ & $63 \%$ & $65 \%$ \\
\hline Prior stroke & $9 \%$ & $10 \%$ & $10 \%$ \\
\hline \multicolumn{4}{|l|}{ Medications } \\
\hline$\beta$-adrenoceptor-blockers & $38 \%$ & $42 \%$ & $40 \%$ \\
\hline Diuretics & $24 \%$ & $27 \%$ & $26 \%$ \\
\hline Antidepressants & $2 \%$ & $4 \%$ & $3 \%$ \\
\hline Major tranquilisers & $2 \%$ & $3 \%$ & $0 \%$ \\
\hline Minor tranquilisers & $7 \%$ & $4 \%$ & $5 \%$ \\
\hline \multicolumn{4}{|l|}{ Non-fasting blood lipids at Screening } \\
\hline Total cholesterol (mmol 1-1) & $7.0 \pm 1.2$ & $7.1 \pm 1.3$ & $6.9 \pm 1.2$ \\
\hline HDL cholesterol $\left(\mathrm{mmol} \mathrm{1}^{-1}\right)$ & $1.16 \pm 0.34$ & $1.17 \pm 0.35$ & $1.16 \pm 0.32$ \\
\hline Calculated LDL cholesterol $\left(\mathrm{mmol}^{-1}\right)$ & $4.8 \pm 1.0$ & $4.8 \pm 1.1$ & $4.7 \pm 1.1$ \\
\hline Triglycerides $\left(\mathrm{mmol} \mathrm{l}^{-1}\right)$ & $2.45 \pm 1.17$ & $2.61 \pm 1.84$ & $2.59 \pm 1.51$ \\
\hline
\end{tabular}

Results are expressed as mean \pm s.d. or as percentages. 
simvastatin group $v s 38$ in placebo group). Most of the 28 surviving patients who did not complete a questionnaire were no longer attending clinic follow-up and were not taking study treatment. Lipid changes at the time of questionnaire completion were similar to those in the whole study, with total serum cholesterol reduced from baseline by $1.8 \pm 0.1 \mathrm{mmol} 1^{-1}(27 \%$ proportional reduction) among those allocated $40 \mathrm{mg}$ daily simvastatin and by $1.7 \pm 0.1 \mathrm{mmol}(25 \%)$ among those allocated $20 \mathrm{mg}$ daily simvastatin, compared with placebo. Most of the reduction in total cholesterol with simvastatin was due to a reduction in LDL cholesterol, with a small increase in HDL cholesterol and a fall in triglyceride levels [16].

Reports of sleep-related symptoms during routine followup (Table 2)

By the time of questionnaire administration, patients attending clinic had been seen an average of seven times following randomization. The numbers of patients completing the sleep questionnaire who had reported any of the possibly sleep-related symptoms (e.g. insomnia, fatigue) routinely enquired about at each visit, who had volunteered sleep-related difficulties (e.g. difficulty getting to sleep), or who used medications that affect sleep patterns were evenly balanced between the treatment groups (Table $2 a$ ). The proportion of visits at which symptoms have ever been reported may better identify a persistent problem, but there were no significant differences in the proportions of visits with reports of insomnia $(15 \%$ of those allocated $40 \mathrm{mg}$ or $20 \mathrm{mg}$ daily simvastatin vs $16 \%$ of those allocated placebo) or other sleep-related problems. Similarly, among patients who did not complete the sleep questionnaire, there were no significant differences between the treatment groups in reports of sleep-related problems (Table $2 b$ ).

Sleep disturbance was never given as the principal reason for stopping study treatment, although two patients allocated $40 \mathrm{mg}$ daily simvastatin were reported to have stopped due to fatigue. Another man allocated $40 \mathrm{mg}$ daily simvastatin stopped his study treatment within 1 week of randomization, principally due to dry eyes and mouth, but also complaining of lethargy and sleep disturbance. Re-challenge with $40 \mathrm{mg}$ daily simvastatin and with 'step-down' doses of $20 \mathrm{mg}$ and $10 \mathrm{mg}$ daily resulted in recurrence of these symptoms. After 18 months, he agreed to a further re-challenge with 1 week each of $20 \mathrm{mg}$ and $40 \mathrm{mg}$ daily simvastatin and of matching placebo, and sleep disturbance did not recur in any period.

More prolonged follow-up (in clinic or by telephone) after administration of the questionnaire reinforces the apparent lack of effect of simvastatin on sleep-related problems. During an average of 286 weeks (i.e. 5.5 years) of follow-up, insomnia had been reported at any time by $121(59 \%)$ of those allocated $40 \mathrm{mg}$ daily simvastatin vs $135(65 \%)$ of those allocated $20 \mathrm{mg}$ daily simvastatin vs $138(67 \%)$ of those allocated placebo (NS). The numbers of patients who had stopped taking study treatment for any reason other than death remained similar in the different treatment groups (72 vs $66 \mathrm{vs}$ 86 ), and there were still no patients who had stopped principally for insomnia.

\section{Validity and reproducibility of sleep questionnaire responses (Tables 3 and 4 )}

The validity of questions $1-4$ in the sleep questionnaire and of the Jenkins Total Sleep Problem score (sum of 1-4) has been investigated previously [17]. Table 3 shows the correlations between the Total Sleep Problem score and the previously unvalidated questions (5-8). These are in the expected directions (e.g. positive correlation between increased score and more frequent dreams/nightmares and are all highly statistically significant (each $2 P=0.0001$ ), but are all relatively low (ranging from 0.2 to 0.4 ). The correlations of responses to these additional questions with each other are also low (as are their correlations with each of questions 1-4: data not shown).

A total of 354 patients completed the questionnaire on two occasions 6 months apart. Moderately good reproducibility of responses was observed, with testretest correlation coefficients exceeding 0.5 (and with similar weighted kappa estimates) for all questions except the added question about changes in sleep duration, which had a correlation coefficient of only 0.23 (and a weighted kappa of 0.25: Table 4). Another of the added questions (about taking prescription sleeping tablets) had much the best reproducibility, while the degree of reproducibility observed with the Jenkins Total Sleep Problem score was similar to that reported previously [17].

Comparisons of responses to sleep questionnaire (Tables 5 and 6)

In response to the sleep questionnaire, the reported frequencies of various sleep events in the past month (Table 5: questions 1-6) were not significantly different between the treatment groups, except that marginally significantly $(2 P<0.05)$ fewer patients allocated simvastatin reported waking several times during the night. This difference was not marked and, given the number of comparisons undertaken, may have occurred by chance alone. Reported duration of sleep during the previous night was similar in the different treatment groups $(421 \pm 75 \mathrm{~min}$ in $40 \mathrm{mg}$ daily simvastatin group vs $408 \pm 90 \mathrm{~min}$ in $20 \mathrm{mg}$ daily simvastatin group vs $415 \pm 82 \mathrm{~min}$ in placebo group). Most patients did not feel that their sleep duration had changed since the start of the study, and there were no significant differences in the proportions who felt that, since entering the study, they slept for a shorter or longer time. There was a trend towards a lower Jenkins Total Sleep Problem score (sum of questions 1-4) with increasing dose of simvastatin, suggesting fewer problems, but this trend 
Table 2 Any reports of sleep-related symptoms made at any time after randomization and before or during the clinic follow up visit at which the sleep questionnaire was administered

\begin{tabular}{rrr}
\hline Simvastatin & Simvastatin & Placebo \\
$40 \mathrm{mg}$ daily & $20 \mathrm{mg}$ daily & control
\end{tabular}

(a) Patients completing a sleep questionnaire Number of patients

191

$72(38 \%)$
$6(3 \%)$
$7(4 \%)$
$5(3 \%)$
$101(53 \%)$

$3(2 \%)$

$0(0 \%)$

$6(3 \%)$

Prostatic symptoms

Medications:

$\beta$-adrenoceptor-blockers

Diuretics

Antidepressants

Major tranquilisers

Minor tranquilisers

$68(36 \%)$
$40(21 \%)$
$5(3 \%)$
$4(2 \%)$
$17(9 \%)$

15

$73(39 \%)$
$8(4 \%)$
$11(6 \%)$
$12(6 \%)$
$107(57 \%)$

$1(1 \%)$

$2(1 \%)$

$3(2 \%)$

$$
\begin{gathered}
76(40 \%) \\
48(25 \%) \\
5(3 \%) \\
5(3 \%) \\
8(4 \%)
\end{gathered}
$$

$5(26 \%)$

$1(5 \%)$

$1(5 \%)$

$1(5 \%)$

$11(58 \%)$
$3(20 \%)$
$0(0 \%)$
$0(0 \%)$
$0(0 \%)$
$8(53 \%)$

$0(0 \%)$

$0(0 \%)$

$0(0 \%)$
$0(0 \%)$
$0(0 \%)$
$0(0 \%)$
$77(41 \%)$

$8(4 \%)$

$13(7 \%)$

$6(3 \%)$

$105(56 \%)$
$2(1 \%)$

$1(1 \%)$

$6(3 \%)$

$78(42 \%)$

$50(27 \%)$

$5(3 \%)$

$5(3 \%)$

$9(5 \%)$

Volunteered symptoms:

Excess sleepiness

Prostatic symptoms

Principal reasons for stopping:

\begin{tabular}{lccc} 
Sleep disturbance & $0(0 \%)$ & $0(0 \%)$ & $0(0 \%)$ \\
Fatigue & $2(6 \%)$ & $0(0 \%)$ & $0(0 \%)$ \\
Unable to attend routine clinics & $4(13 \%)$ & $7(29 \%)$ & $6(16 \%)$ \\
Refused to take tablets or attend & $13(41 \%)$ & $10(42 \%)$ & $17(45 \%)$ \\
Any other reason & $13(41 \%)$ & $7(29 \%)$ & $15(39 \%)$ \\
\hline
\end{tabular}

$\dagger$ Patients who did not complete questionnaires include those clinic attenders who refused and those being followed up by telephone who were not approached (5 vs $10 \mathrm{vs} 7$ ), and those no longer being followed up in clinic or by telephone (10 vs 9 vs 13).

was not significant, either overall or when subdivided by baseline serum cholesterol (Table 6). Analyses restricted to those patients considered compliant with their allocated study treatment (i.e. 'on-treatment' comparisons) produced similar results, with no clear differences between the treatment groups (data not shown).

\section{Discussion}

It had been suggested, based on selected uncontrolled case reports $[3,5,6]$ and the results from one randomized comparison of just 22 days of lovastatin $v$ s pravastatin in 12 subjects [12], that lovastatin and 
Table 3 Correlations (and $P$ values) between additional sleep questions (5-8) and Jenkins Total Sleep Problem score

\begin{tabular}{|c|c|c|c|c|}
\hline $\begin{array}{l}\text { Questions about sleep events } \\
\text { (and question number) }\end{array}$ & $\begin{array}{c}\text { Vivid } \\
\text { dreams/ } \\
\text { nightmares } \\
\text { (5) }\end{array}$ & $\begin{array}{c}\text { Take } \\
\text { sleeping } \\
\text { tablets } \\
\text { (6) }\end{array}$ & $\begin{array}{c}\text { Sleep } \\
\text { duration } \\
\text { last night } \\
\text { (7) }\end{array}$ & $\begin{array}{c}\text { Change } \\
\text { in sleep } \\
\text { duration } \\
\text { (8) }\end{array}$ \\
\hline Take sleeping tablets (6) & $\begin{array}{r}0.04 \\
(0.2)\end{array}$ & - & - & - \\
\hline Sleep duration last night (7) & $\begin{array}{c}-0.11 \\
(<0.01)\end{array}$ & $\begin{array}{r}-0.02 \\
(0.4)\end{array}$ & - & - \\
\hline Change in sleep duration (8) & $\begin{array}{c}-0.11 \\
(<0.01)\end{array}$ & $\begin{array}{r}0.03 \\
(0.3)\end{array}$ & $\begin{array}{c}0.27 \\
(<0.0001)\end{array}$ & - \\
\hline Total Sleep Problem score (sum of 1-4) & $\begin{array}{c}0.33 \\
(<0.0001)\end{array}$ & $\begin{array}{c}0.20 \\
(<0.0001)\end{array}$ & $\begin{array}{l}-0.40 \\
(<0.0001)\end{array}$ & $\begin{array}{l}-0.35 \\
(<0.0001)\end{array}$ \\
\hline
\end{tabular}

Complete data were available for 543 patients, and these contribute to the analyses.

Table 4 Correlations between responses to two administrations of the sleep questionnaire 6 months apart

\begin{tabular}{lcc}
\hline $\begin{array}{l}\text { Questions about sleep events } \\
\text { (and question number) }\end{array}$ & $\begin{array}{c}\text { Test-retest } \\
\text { correlation } \\
\text { coefficient }\end{array}$ & $\begin{array}{c}\text { Weighted kappa } \\
(\text { SE })^{*}\end{array}$ \\
\hline Trouble falling asleep (1) & 0.64 & $0.54(0.05)$ \\
Wake up several times per night (2) & 0.58 & $0.45(0.03)$ \\
Trouble staying asleep (3) & 0.54 & $0.46(0.04)$ \\
Wake up tired (4) & 0.64 & $0.52(0.04)$ \\
Vivid dreams/nightmares (5) & 0.67 & $0.53(0.05)$ \\
Take sleeping tablets (6) & 0.83 & $0.77(0.06)$ \\
Sleep duration last night (7) $\dagger$ & 0.53 & $0.42(0.03)$ \\
Change in sleep duration (8) & 0.23 & $0.25(0.08)$ \\
Total Sleep Problem score (sum of 1-4) & 0.68 & $0.49(0.03)$ \\
\hline
\end{tabular}

354 patients completed the sleep questionnaire on two occasions 6 months apart. Responses on both occasions were available from a similar number of patients for each question (ranging from 342 to 352 ), except that paired responses for question 8 were available for only 316 .

*All weighted kappa scores are statistically significant at $2 P<0.01$.

$\dagger$ Categories of question 7 were created by dividing the responses into five groups of similar size.

Table 6 Jenkins Total Sleep Problem score subdivided by baseline serum cholesterol level

\begin{tabular}{lccc}
\hline & \multicolumn{3}{c}{ Total Sleep Problem score $\dagger$} \\
\cline { 2 - 4 } & $\begin{array}{c}\text { Simvastatin } \\
\text { Baseline total }\end{array}$ & $\begin{array}{c}\text { Simvastatin } \\
\text { cholesterol }\left(\mathrm{mmol} \mathrm{l}^{-1}\right)\end{array}$ & $\begin{array}{c}\text { Placebo } \\
\text { control } \\
(191)\end{array}$ \\
\hline$<6.0$ & $3.5 \pm 1.8$ & $3.1 \pm 1.9$ & $3.8 \pm 1.5$ \\
$6.1-7.0$ & $3.7 \pm 1.5$ & $3.1 \pm 1.8$ & $4.8 \pm 1.2$ \\
$>7.0$ & $2.9 \pm 1.7$ & $4.6 \pm 1.5$ & $3.8 \pm 1.5$ \\
All patients & $3.2 \pm 1.7$ & $3.7 \pm 1.7$ & $4.1 \pm 1.4$ \\
\hline
\end{tabular}

$\dagger$ Geometric mean \pm s.d.: no significant differences in scores either between any (i.e. $40 \mathrm{mg}$ or $20 \mathrm{mg}$ daily) simvastatin $v s$ placebo or between $40 \mathrm{mg} v \mathrm{~s} 20 \mathrm{mg}$ daily simvastatin.

simvastatin (but not pravastatin) might have adverse effects on sleep patterns. Subsequently, several randomized trials have studied the effects of different HMG-CoA reductase inhibitors on sleep in sleep laboratories and/or by questionnaire, but their results do not tend to confirm the early reports. For example, in one small trial there were no significant differences at 21 days between the 65 patients allocated lovastatin, 
Table 5 Percentages of patients reporting the frequency with which particular sleep events occurred in the previous month

\begin{tabular}{|c|c|c|c|c|c|c|c|}
\hline Question (and question number) & $\begin{array}{l}\text { Number of nights* } \\
\text { Score }\end{array}$ & $\begin{array}{c}\text { None } \\
0\end{array}$ & $\begin{array}{c}1-3 \\
1\end{array}$ & $\begin{array}{c}4-7 \\
2\end{array}$ & $\begin{array}{c}8-14 \\
3\end{array}$ & $\begin{array}{c}15-21 \\
4\end{array}$ & $\begin{array}{c}22-31 \\
5\end{array}$ \\
\hline \multicolumn{8}{|l|}{ How often in the past month did you: } \\
\hline \multirow[t]{3}{*}{ Have trouble falling asleep? (1) } & $40 \mathrm{mg}$ daily $\mathrm{S}$ & 69 & 10 & 8 & 2 & 5 & 6 \\
\hline & $20 \mathrm{mg}$ daily $\mathrm{S}$ & 62 & 11 & 9 & 3 & 6 & 9 \\
\hline & Placebo & 67 & 12 & 9 & 4 & 2 & 6 \\
\hline \multirow[t]{3}{*}{ Wake up several times per night? (2) } & $40 \mathrm{mg}$ daily $\mathrm{S}$ & 33 & 12 & 11 & 12 & 8 & 24 \\
\hline & $20 \mathrm{mg}$ daily $\mathrm{S}$ & 30 & 16 & 13 & 7 & 7 & 27 \\
\hline & Placebo & 24 & 11 & 16 & 11 & 5 & 33 \\
\hline \multirow{3}{*}{$\begin{array}{l}\text { Have trouble staying asleep } \\
\quad \text { (including waking far too early)? (3) }\end{array}$} & $40 \mathrm{mg}$ daily $\mathrm{S}$ & 59 & 6 & 8 & 4 & 6 & 16 \\
\hline & $20 \mathrm{mg}$ daily $\mathrm{S}$ & 58 & 6 & 10 & 7 & 5 & 14 \\
\hline & Placebo & 52 & 10 & 9 & 8 & 4 & 18 \\
\hline \multirow{3}{*}{$\begin{array}{l}\text { Wake up after your usual amount of } \\
\text { sleep feeling tired and worn out? (4) }\end{array}$} & $40 \mathrm{mg}$ daily $\mathrm{S}$ & 62 & 10 & 10 & 6 & 6 & 6 \\
\hline & $20 \mathrm{mg}$ daily $\mathrm{S}$ & 56 & 13 & 10 & 5 & 2 & 15 \\
\hline & Placebo & 59 & 14 & 12 & 4 & 5 & 7 \\
\hline \multirow[t]{3}{*}{ Have vivid dreams or nightmares? (5) } & $40 \mathrm{mg}$ daily $\mathrm{S}$ & 72 & 12 & 5 & 5 & 2 & 4 \\
\hline & $20 \mathrm{mg}$ daily $\mathrm{S}$ & 67 & 16 & 5 & 5 & 4 & 3 \\
\hline & Placebo & 70 & 14 & 8 & 3 & 3 & 2 \\
\hline \multirow{4}{*}{$\begin{array}{l}\text { Take a prescription sleeping tablet } \\
\text { to help you sleep? (6) }\end{array}$} & $40 \mathrm{mg}$ daily $\mathrm{S}$ & 88 & 1 & 2 & 2 & 0 & 7 \\
\hline & $20 \mathrm{mg}$ daily $\mathrm{S}$ & 91 & 1 & 1 & 1 & 1 & 5 \\
\hline & Placebo & 92 & 1 & 1 & 1 & 1 & 5 \\
\hline & & $<360$ & $360-399$ & $400-449$ & $450-479$ & $480+$ & \\
\hline \multirow{4}{*}{$\begin{array}{l}\text { Sleep duration }(\mathrm{min}) \text { during the } \\
\text { previous night }(7) \dagger\end{array}$} & $40 \mathrm{mg}$ daily $\mathrm{S}$ & 15 & 21 & 17 & 21 & 26 & \\
\hline & $20 \mathrm{mg}$ daily $\mathrm{S}$ & 21 & 17 & 21 & 17 & 23 & \\
\hline & Placebo & 17 & 21 & 22 & 15 & 26 & \\
\hline & & Shorter & Same & Longer & & & \\
\hline \multirow{3}{*}{$\begin{array}{l}\text { Has your average sleep duration changed } \\
\text { since you started this study? ( } 8 \text { ) }\end{array}$} & $40 \mathrm{mg}$ daily $\mathrm{S}$ & 12 & 86 & 2 & & & \\
\hline & $20 \mathrm{mg}$ daily $\mathrm{S}$ & 14 & 81 & 5 & & & \\
\hline & Placebo & 8 & 88 & 4 & & & \\
\hline
\end{tabular}

191 patients allocated $40 \mathrm{mg}$ daily simvastatin, 189 allocated $20 \mathrm{mg}$ daily simvastatin and 187 allocated placebo completed sleep questionnaires, with only slight variations in the numbers of responses for each question (except that 36 patients who gave 'Don't know' responses to the last question were excluded from that comparison). Patients not attending study clinics were not asked to complete a questionnaire: all were off study treatment and none had been reported to have stopped treatment due to sleep disturbance.

*No significant differences in proportions between any (i.e. $40 \mathrm{mg}$ or $20 \mathrm{mg}$ daily) simvastatin $v \mathrm{~s}$ placebo or between $40 \mathrm{mg} v \mathrm{~s}$ $20 \mathrm{mg}$ daily simvastatin, except that significantly $(2 P<0.05)$ fewer patients allocated simvastatin than those allocated placebo reported that they woke several times per night.

$\dagger$ Categories of the question about sleep duration during the previous night were created by dividing the responses into five groups of similar size.

pravastatin or placebo in any of the objective sleep laboratory measures, standardized measures of daytime sleepiness or subjective measures of sleep used [10]. Differences in daytime performance with lovastatin were reported, but these represented changes from baseline and not significant differences between the treatment groups. In another small sleep laboratory study, the only significant difference from placebo was that lovastatin, but not pravastatin, was associated with fewer wakenings [9]. A larger questionnaire-based study found no differences in the Jenkins Total Sleep Problem score between the 500 patients allocated simvastatin $v$ s pravastatin after 6,12 or 18 weeks of treatment [14]. And, although one double-blind trial in 672 patients did observe a lower questionnaire-based sleep score at 18 weeks with pravastatin compared with lovastatin, this small difference was only marginally significant and it was not seen after 6 or 12 weeks of treatment [15].
These previous randomized studies had a number of limitations: in particular, they involved small numbers of patients, very short duration of treatment and/or the absence of an untreated control group or period. The much larger placebo-controlled EXCEL trial did involve more prolonged treatment and no excess of insomnia was reported with one year of lovastatin, but information about sleep disturbance was not sought systematically in that study [19].

By contrast, the Oxford Cholesterol Study involved more than 600 patients and compared the effects of prolonged use of simvastatin (average of 88 weeks) with those of placebo-control on systematically sought measures of sleep disturbance. Compliance with study treatment was comparable with that of other long-term studies [19], and simvastatin was producing a substantial reduction in total cholesterol $\left(1.7-1.8 \mathrm{mmol}^{-1}\right)$ at the time the sleep questionnaire was being completed. 
Despite this, no adverse effects of simvastatin were observed on perceived sleeping problems, on duration of sleep or on the use of sleep-enhancing medications. Nor were there any significant differences between the treatment groups in withdrawals from study treatment for possible sleep-related problems or for any other reasons. The only significant difference observed was that fewer patients allocated simvastatin reported frequent waking during the night (although, given the number of comparisons made, this small difference may have occurred by chance). A few patients experienced some difficulty in completing the questionnaire, partly because of a failure to respond with respect to the numbers of nights with problems in the previous month. Another source of confusion was for men with nocturia, which was usually related to prostatic symptoms: it was suggested that nights disturbed by nocturia should be counted. (No differences in prostatic symptoms were reported between the treatment groups: Table 2.) But, although these difficulties with the questionnaire may have increased the random errors slightly, they should not have introduced any systematic bias. Furthermore, more prolonged routine follow-up to 5.5 years reinforced the sleep questionnaire findings, with no difference in reports of any sleep-related problems emerging.

The information recorded on the sleep questionnaire and routinely at each Follow-up visit in the Oxford Cholesterol Study was subjective, but the study was randomised, double-blind, placebo-controlled, and involved several hundred patients, so any differences in sleep that were relevant to patients would be expected to have become apparent. In conclusion, therefore, the results of the present study, along with those from other studies, do not provide any good evidence of significant adverse effects on sleep of prolonged treatment with simvastatin or other HMG-CoA reductase inhibitors.

We are particularly grateful to all the patients, and their doctors, who agreed to participate in this study. Funding was provided by Merck Sharp \& Dohme, who also supplied calendar-packed treatment, but the study was designed, conducted and analysed independently of the pharmaceutical company. Dr Collins is supported by a British Heart Foundation Senior Research Fellowship. Mavis Keeble helped to conduct the study clinics and to administer the questionnaires, and Gale Mead provided secretarial support. Acknowledgements to the many others involved in the study are given in Keech et al. [16].

\section{References}

1 Grundy SM. HMG-CoA reductase inhibitors for hypercholesterolemia. N Engl J Med 1988; 319: 24-33.

2 Botti RE, Triscari J, Pan HY, Zayat J. Concentrations of pravastatin and lovastatin in cerebrospinal fluid in healthy subjects. Clin Neuropharm 1988; 14: 256-261.
3 Shaefer EJ. HMG-CoA reductase inhibitors for hypercholesterolemia. N Engl J Med 1988; 319: 1222 (letter).

4 Black DM, Lamkin G, Olivera EH, Laskarzewski PM, Stein EA. Sleep disturbance and HMG CoA reductase inhibitors. JAMA 1990; 264: 1105 (letter).

5 Barth JD, Kruisbrink OAE, Van Dijk AL. Inhibitors of hydroxymethylglutaryl coenzyme A reductase for treating hypercholesterolaemia. Br Med J 1991; 301: 669 (letter).

6 Sinzinger H, Mayr F, Schmid P, Granegger S, O’Grady J, Peskar BA. Sleep disturbance and appetite loss after lovastatin. Lancet 1994; 343: 973 (letter).

7 Gillan JC, Byerley WF. The diagnosis and management of insomnia. N Engl J Med 1988; 322: 239-248.

8 Harrison RWS, Ashton CH. Do cholesterol-lowering agents affect brain activity? A comparison of simvastatin, pravastatin, and placebo in healthy volunteers. $\mathrm{Br} \mathrm{J} \mathrm{Clin}$ Pharmacol 1994; 37: 231-236.

9 Partinen M, Pihl S, Strandberg T, et al. Comparison of effects on sleep of lovastatin and pravastatin in hypercholesterolemia. Am J Cardiol 1994; 73: 876-880.

10 Roth, T., Richardson, GR, Sullivan, JP, Lee, RM, Merlotti, L., Roehrs, T. Comparative effects of pravastatin and lovastatin on nighttime sleep and daytime performance. Clin Cardiol 1992; 15, 426-432.

11 Stalenhoef AFH, Lansberg PJ, Kroon AA, et al. Treatment of primary hypercholesterolaemia. Short-term efficacy and safety of increasing doses of simvastatin and pravastatin: a double-blind comparative study. J Intern Med 1993; 234(1): 77-82.

12 Vgontzas AN, Kales A, Bixler EO, Manfredi RL, Tyson KL. Effects of lovastatin and pravastatin on sleep efficiency and sleep stages. Clin Pharmacol Ther 1991; 50: 730-737.

13 Eckernas SA, Roos BE, Kvidal P, et al. The effects of simvastatin and pravastatin on objective and subjective measures of nocturnal sleep: a comparison of two structurally different HMG CoA reductase inhibitors in patients with primary moderate hypercholesterolaemia. Br J Clin Pharmacol 1993; 35: 284-289.

14 Simvastatin Pravastatin Study Group. Comparison of the efficacy, safety and tolerability of simvastatin and pravastatin for hypercholesterolemia. Am J Cardiol 1993; 71: $1408-1414$.

15 Lovastatin Pravastatin Study Group. A multicenter comparative trial of lovastatin and pravastatin in the treatment of hypercholesterolemia. Am J Cardiol 1993; 71: 810-815.

16 Keech A, Collins R, MacMahon S, et al. for the Oxford Cholesterol Study Group. Three-year follow-up of the Oxford Cholesterol Study: assessment of the efficacy and safety of simvastatin in preparation for a large mortality study. Eur Heart J 1994; 15: 255-269.

17 Jenkins CD, Stanton B-A, Niemcryk SJ, Rose RM. A scale for the estimation of sleep problems in clinical research. J Clin Epidemiol 1988; 41: 313-321.

18 Cohen J. Weighted Kappa: nominal scale agreement with provision for scaled disagreement or partial credit. Psychol Bulletin 1968; 70: 213-220.

19 Bradford RH, Shear CL, Athanassios N, et al. Expanded Clinical Evaluation of Lovastatin (EXCEL) Study results. Arch Intern Med 1991; 151: 43-49.

(Received 17 October 1995, accepted 23 April 1996) 